\title{
Knowledge, Attitude and Practice of Malaysian Public University Students on Risk Factors for Cardiovascular Diseases
}

\author{
Mardhiah Mahada Ibrahim ${ }^{1}$, Nor Azlina A. Rahman ${ }^{1 *}$, Nor Iza A. Rahman², Mainul Haque \\ ${ }^{1}$ Department of Biomedical Science, Kulliyyah of Allied Health Sciences, International Islamic University Malaysia, 25200 Kuantan, Pahang, Malaysia . \\ ${ }^{2}$ Unit of Pathology, Faculty of Medicine, Universiti Sultan Zainal Abidin, 20400 Kuala Terengganu, Malaysia. ${ }^{3}$ Unit of Pharmacology, Faculty of Medicine, \\ Universiti Sultan Zainal Abidin, 20400 Kuala Terengganu, Malaysia.
}

\section{ARTICLE INFO}

Article history:

Received on: 18/11/2015

Revised on: 06/12/2015

Accepted on: 21/12/2015

Available online: 27/02/2016

Key words:

KAP, University Students,

Cardiovascular Disease,

Malaysia.

\begin{abstract}
Cardiovascular diseases (CVD) account for 30\% of all deaths in Malaysia. Major risk factors for CVD include age, gender, heredity, hypertension, cigarette smoking, hypercholesterolemia, diabetes, obesity and physical inactivity. The current study was conducted to understand the knowledge, attitude and practice (KAP) of University students regarding cardiovascular diseases. This is a cross-sectional study using a stratified random sampling method. Students of all faculties of International Islamic University Malaysia (IIUM) in Kuantan Campus were included. The respondents were randomly selected from each faculty. The sample size was 163. KAP questionnaire was developed and distributed to the respondents involved. The data collected was analyzed using SPSS version 17.0. The mean and standard deviation of the knowledge, attitude and practice scores were $42.98 \pm 2.46,57.12 \pm 5.73$ and $26.7 \pm 3.507$, respectively. Significant difference on knowledge scores were found between different faculties $(p<0.001)$, also on attitude and practice scores in comparison between different genders $(p=0.005$ and 0.017 , respectively). This study also shows a significant positive correlation between attitude and practice scores $(r=+0.354, p<0.001)$. IIUM students should engage in exercise more and develop a healthier lifestyle.
\end{abstract}

\section{INTRODUCTION}

Cardiovascular diseases (CVD) are the number one cause of death globally (WHO, 2011a). CVD is responsible for $30 \%$ of all deaths in Malaysia with hypertension topping the list (Rampal, 2011; WHO, 2011b). CVD is the main cause of deaths in many developing countries as well. Risk factors for cardiovascular disease are divided into two categories; major and minor contributing factors (Grundy et al., 1999; Wilson et al., 1998). Major risk factors include high blood pressure, cigarette smoking, high cholesterol level, diabetes, obesity and physical inactivity. The minor contributing risk factors include stress, sex hormone intake, birth control pills intake and alcohol intake (Texas Heart Institute, 2015). Age, gender and heredity are also known as non-modifiable risk factors. Other factors such as smoking, obesity and physical inactivity can be considered as modifiable risk factors because it can be controlled and changed (Cardiovascular Consultants, 2006).

\footnotetext{
* Corresponding Author

Email: nazara@iium.edu.my
}

In Malaysia, CVD has been the major cause of deaths since the early 70's. Coronary heart disease (CHD) for example, accounted for $19.3 \%(12,412)$ mortality in men and the figure was even higher in women, $21.2 \%(9,746)$. The death rate due to CVD among women was $26.1 \%$ in 2006, which was $0.7 \%$ higher than in 2005. Most of the deaths were due to heart attack (Rosediani et al., 2012). The estimated incidence of CHD in Malaysia is 141 per 100,000 population. The increasing number of young people having CVD and its risk factors have become a major concern since the transition of urbanization in many developing countries including Malaysia. The awareness of the younger generation regarding CVD is very significant to reduce its prevalence. Therefore, it is expected that young people will adhere to healthy lifestyles (Institute of Medicine, 2010; Gaziano et al., 2010; Smith et al., 2012). Assessing baseline KAP of young people such as university students on CVD issues are crucial and important. Many studies of KAP were conducted to understand the pattern of the disease occurrence and its behavior among society. An appropriate assessment on KAP, its factors and understanding is helpful in preventing and necessitates a lifelong adoption of a healthy lifestyle (Linda, 2007). 
The purpose of the study described here is to measure the KAP among students of International Islamic University Malaysia (IIUM) in Kuantan Campus about the risks of CVD, to compare the KAP levels between different soci-demographic factors and to assess the correlation between the KAP regarding CVD risk factors.

\section{MATERIALS AND METHODS}

This is a cross-sectional descriptive and analytical study to assess the KAP regarding risk factors of CVD among students of IIUM Kuantan, Malaysia. This study was conducted at IIUM Kuantan Campus between March to May 2012. A set of KAP questionnaire was developed and distributed to the participants. The questionnaire was validated by conducting the pre-testing among 15 students in a pilot study. The content validity of the questionnaire was verified by expert of IIUM. The questionnaires were distributed to the selected undergraduate students of all the six faculties in IIUM Kuantan Campus; namely the Faculty of Medicine, Pharmacy, Dentistry, Nursing, Allied Health Sciences and Science, given some interval time and collected back after they have completed the questionnaire. The stratified random sampling method was utilized in selecting the participants. The inclusion criteria for the participants were age of 18 years old and above of both genders, which include Year 1 to Year 4 from each faculty. The students who have CVD were excluded from this survey.

The sample size calculated was 163 , inclusive of the $10 \%$ non-response rate. The confidence level chosen was 95\%, and $56 \%$ were chosen for the value of $p$ as it was the percentage for good knowledge score among women in North-East Coast Malaysia (Rosediani et al., 2012). In order to avoid getting a very big sample size, which might not be manageable, 0.08 precision value has been chosen. The questionnaire consisted of four main sections with several sub-sections. The first section was the demographic factors such as age, gender, faculty, year of study and family history of CVD. The second section was close-ended questions on knowledge regarding CVD risk factors and its preventive measure with two sub-sections focused on the sources of CVD information and the diseases and conditions related to CVD. The third section comprised of the attitude questions towards the risk factors of CVD using the Likert-scale type of questions. It had five choices ranging from "Strongly Agree" to "Strongly Disagree" items. The fourth section used the scheme of four answer choices: "Always", "Frequent", "Seldom" and "Never", centered on the practice towards the prevention of CVD risk factors [Always means at all times, Frequent means happening often, Seldom means not often or almost never, Never means not ever or not at any time]. All the data that had been collected was analyzed using Statistical Package for Social Science (SPSS) version 17.0. Descriptive statistics (frequency and percentage) were used to describe the socio-demographic characteristics and the KAP, Anova test was used to compare the KAP between the different socio-demographic characteristics and correlation test was used to find the correlation between the KAP regarding CVD risk factors.

\section{RESULTS}

\section{Socio-demographic characteristics}

Out of 163 students randomly selected from the study population, four did not complete the questionnaire, leaving for analysis 159 subjects who constituted the study sample. The average age of the respondents is $22.5 \pm 1.3$ years old with the majority $(99.4 \%, 158)$ of them were single. $22.6 \%$ (36) and $77.4 \%$ (123) were males and females, respectively. $16 \%, 21 \%, 13 \%$, $15 \%, 21 \%$, and $14 \%$ of the respondents from the faculty of Science, Pharmacy, Medicine, Allied Health Sciences, Dentistry and Nursing, respectively, were involved in this research. $21 \%$, $30 \%, 27 \%$ and $22 \%$ of the respondents were from Year 1, 2, 3 and 4 respectively. $39 \%, 30 \%, 6 \%$, and $25 \%$ of the respondents' fathers, mothers, siblings or others have a history of CVD, respectively. $58 \%, 19 \%, 13 \%$, and $10 \%$ of the respondents stated that their relatives suffered from hypertension, heart attack, stroke or other types of chronic diseases, respectively. The sociodemographic characteristics of the respondents are summarized in Table 1 .

Table 1: Socio-demographic Characteristic of Respondents

\begin{tabular}{|c|c|c|c|}
\hline \multirow[t]{2}{*}{ Total } & $\begin{array}{c}\text { Male }(\mathbf{n}=36) \\
\text { No }(\%)\end{array}$ & $\begin{array}{c}\text { Female }(n=123) \\
\text { No }(\%)\end{array}$ & $\begin{array}{c}\text { Total }(\mathbf{n}=159) \\
\text { No }(\%) \\
\end{array}$ \\
\hline & $36(22.6)$ & $123(77.4)$ & $159(100)$ \\
\hline \multicolumn{4}{|l|}{ Faculty } \\
\hline Science & $5(19.2)$ & $21(80.8)$ & $26(16.4)$ \\
\hline Pharmacy & $9(28.1)$ & $23(71.9)$ & $32(20.1)$ \\
\hline Medicine & $9(42.9)$ & $12(57.1)$ & $21(13.2)$ \\
\hline Allied Health & $6(25.0)$ & $18(75.0)$ & $24(15.1)$ \\
\hline \multicolumn{4}{|l|}{ Sciences } \\
\hline Dentistry & $4(11.8)$ & $30(88.2)$ & $34(21.4)$ \\
\hline Nursing & $3(13.6)$ & $19(86.4)$ & $22(13.8)$ \\
\hline \multicolumn{4}{|l|}{ Year of Study } \\
\hline 1 & $8(24.2)$ & $25(75.8)$ & $33(20.8)$ \\
\hline 2 & $9(18.8)$ & $39(81.3)$ & $48(30.2)$ \\
\hline 3 & $12(27.9)$ & $31(72.1)$ & $43(27.0)$ \\
\hline 4 & $7(20.0)$ & $28(80.0)$ & $35(22.0)$ \\
\hline \multicolumn{4}{|l|}{ Marital Status } \\
\hline Single & $36(22.8)$ & $122(77.2)$ & $158(99.4)$ \\
\hline Married & $0(0.0)$ & $1(100.0)$ & $1(0.6)$ \\
\hline \multicolumn{4}{|l|}{ Family History } \\
\hline Father & $13(26.5)$ & $36(73.5)$ & $49(39.2)$ \\
\hline Mother & $8(21.1)$ & $30(78.9)$ & $38(30.4)$ \\
\hline Siblings & $1(14.3)$ & $6(85.7)$ & $7(5.6)$ \\
\hline Others & $6(19.4)$ & $25(80.6)$ & $31(24.8)$ \\
\hline \multicolumn{4}{|c|}{ Type of other CVD History } \\
\hline Heart Attack & $5(19.2)$ & $21(80.8)$ & $26(19.0)$ \\
\hline Hypertension & $17(21.5)$ & $62(78.5)$ & $79(57.7)$ \\
\hline Stroke & $4(22.2)$ & $14(77.8)$ & $18(13.1)$ \\
\hline Others & $4(28.6)$ & $10(71.4)$ & $14(10.2)$ \\
\hline
\end{tabular}

\section{KAP levels Regarding CVD Risk Factors}

Most of the respondents had learned about CVD in the classroom $(91 \%, 144)$, also from books $(82 \%, 130)$ and the internet $(82 \%, 130) .58 \%, 95 \%, 87 \%, 97 \%, 98 \%, 97 \%, 96 \%$ of the respondents correctly knew that CVD is associated with other diseases like diabetes, hypertension, stroke, heart attack, allergy, cancer and asthma, respectively. Again, 80\%, 94\%, 98\%, 87\%, 
$68 \%, 77 \%$, and $71 \%$ of the respondents correctly knew that CVD is associated with certain disease conditions like stress, obesity, hypocholesteremia, smoking, sedentary lifestyle, high abdominal fat, and lack of sleep, respectively. The mean and standard deviation of total knowledge scores is $42.98 \pm 2.46$ with a median of 43 . The total knowledge scores ranged between 36 and 48. The statement with the highest proportion of correct responses is "Prayer can help to reduce stress" $(100 \%, 159)$ followed by "If you have a slim body, you don't need to exercise" (99\%, 157). However, only 27\% (43) respondents answered "True" as the correct answer for "Tobacco cessation programs are available in your hometown", while 41\% (66) answered "False" for "Most CVD cases were not necessarily hereditary". Again, 55\% (88) opined false for "Doing housework as an exercise is enough for a day". The details are shown in Table 2.

The total attitude scores were $57.12 \pm 5.73$ with a median of 57. The total attitude score is ranged between 26 and 70 .
The item with the highest proportion of positive attitude was "I know smoking is bad for health" $(93.7 \%, 149)$ and "I should be doing exercise to maintain a healthy lifestyle" $(87.4 \%, 139)$. Among the lowest correct answers given was for the statement of "Sometimes I eat supper late at night before sleep" $(8.2 \%, 13)$, "I prefer to play with my laptop instead of doing exercise" $(6.9 \%, 11)$ and also "I choose to eat or buy fast food when going out with friends" $(6.3 \%, 10)$, where the expected response is "Strongly Disagree". The details are shown in Table 3. The mean total scores for practice is $26.7 \pm 3.51$ with a median of 27 and ranging from 16 to 37 . In this study, practice on healthy lifestyles was not very good. Only $3.1 \%$ (5) never took fast food and $13.8 \%$ (11) always spend their leisure time to exercise. Despite that, there were $51.6 \%$ (82) of the respondents claimed that they walk for at least 10 minutes to places like café, mosque and between two classes. Moreover, $47.2 \%$ (75) admitted to always taking vegetables in their diet. The details are shown in Table 4.

Table 2: Knowledge on CVD Risk Factors and the Preventive Measure (N=159).

\begin{tabular}{|c|c|c|c|}
\hline \multirow{3}{*}{ Statements } & \multicolumn{3}{|c|}{ Frequency } \\
\hline & True & False & Don't Know \\
\hline & $\mathrm{n}(\%)$ & n $(\%)$ & $\mathrm{n}(\%)$ \\
\hline Cardiovascular disease (CVD) is the leading cause of death in Malaysia & $135(84.9) *$ & $11(6.9)$ & $13(8.2)$ \\
\hline Light walking is a preventive factor for CVD & $123(77.4)^{*}$ & $8(5.0)$ & $28(17.6)$ \\
\hline Adequate exercise can prevent CVD & $152(95.6)^{*}$ & $1(0.6)$ & $6(3.8)$ \\
\hline Eating fruits or vegetable is able to prevent from CVD & $124(78.0)^{*}$ & $16(10.1)$ & $19(11.9)$ \\
\hline Most CVD cases are hereditary & $60(37.7)$ & $66(41.5)^{*}$ & $33(20.8)$ \\
\hline Controlling high fat food consumption is essential & $149(93.7)^{*}$ & $9(5.7)$ & $1(0.6)$ \\
\hline Cardiovascular disease is a disease that is related to heart & $150(94.3) *$ & $6(3.8)$ & $3(1.9)$ \\
\hline Cardiovascular disease is a disease that is related to blood vessels & $138(86.8)^{*}$ & $10(6.3)$ & $11(6.9)$ \\
\hline Tobacco cessation programs are available in your hometown & $43(27.0)^{*}$ & $59(37.1)$ & $57(35.8)$ \\
\hline Irregular eating patterns has no harm to your health & $8(5.0)$ & $140(88.1)^{*}$ & $11(6.9)$ \\
\hline Cardiovascular disease is a disease of women only & $1(0.6)$ & $154(96.9) *$ & $4(2.5)$ \\
\hline Doing housework as an exercise is enough for a day & $45(28.3)$ & $87(54.7)^{*}$ & $27(17.0)$ \\
\hline If you have a slim body, you don't need to exercise & $1(0.6)$ & $157(98.7)^{*}$ & $1(0.6)$ \\
\hline Cardiovascular disease can occur to young people & $149(93.7)^{*}$ & $6(3.8)$ & $4(2.5)$ \\
\hline High density lipoprotein (HDL) is a good type of cholesterol & $110(69.2)^{*}$ & $29(18.2)$ & $20(12.6)$ \\
\hline BMI of more than 30 is considered as obese & $133(83.6)^{*}$ & $13(8.2)$ & $13(8.2)$ \\
\hline Prayer can help to reduce stress & $159(100.0) *$ & $0(0.0)$ & $0(0.0)$ \\
\hline
\end{tabular}

Prayer can help to reduce stres

*Expected answer

The highest response is in bold

Table 3: Attitude regarding Risk Factors of CVD and its prevention $(n=159)$.

\begin{tabular}{|c|c|c|c|c|c|}
\hline \multirow[t]{2}{*}{ Statements } & \multicolumn{5}{|c|}{ Frequency, n(\%) } \\
\hline & Strongly Disagree & Disagree & Uncertain & Agree & Strongly Agree \\
\hline I should be doing exercise to maintain a healthy lifestyle & $2(1.3)$ & 0 & 0 & $18(11.3)$ & $139(87.4) *$ \\
\hline $\begin{array}{l}\text { If I need to go to places somewhere near, I choose to walk rather than } \\
\text { taking any other mean of transportation. E.g. Going to class or café }\end{array}$ & $8(5.0)$ & $11(6.9)$ & $35(22.0)$ & $53(33.3)$ & $52(32.7)^{*}$ \\
\hline I know smoking is bad for health. & $2(1.3)$ & $1(0.6)$ & 0 & $7(4.4)$ & $149(93.7)^{*}$ \\
\hline I should maintain my weight according to my body mass index (BMI) & $2(1.3)$ & $4(2.5)$ & $3(1.9)$ & $31(19.5)$ & $119(74.8)^{*}$ \\
\hline I should take less oily food for healthy lifestyle & $2(1.3)$ & 0 & $1(0.6)$ & $37(23.3)$ & $119(74.8) *$ \\
\hline I prefer to play with my laptop instead of doing exercise & $11(6.9)^{*}$ & $33(20.8)$ & $37(23.3)$ & $39(24.5)$ & $39(24.5)$ \\
\hline I read the nutrition information of each product that I intended to buy & $7(4.4)$ & $27(17.0)$ & $58(36.5)$ & $46(28.9)$ & $21(13.2)^{*}$ \\
\hline I choose to eat or buy fast food when going out with friends & $10(6.3)^{*}$ & $60(37.7)$ & $48(30.2)$ & $27(17.0)$ & $14(8.8)$ \\
\hline I can manage my stress & $1(0.6)$ & $7(4.4)$ & $68(42.8)$ & $64(40.3)$ & $19(11.9)^{*}$ \\
\hline I should avoid drinking carbonated drinks & $3(1.9)$ & $6(3.8)$ & $9(5.7)$ & $55(34.6)$ & $86(54.1)^{*}$ \\
\hline Sometimes I eat supper late at night before sleep & $13(8.2)^{*}$ & $76(47.8)$ & $27(17.0)$ & $24(15.1)$ & $19(11.9)$ \\
\hline I believe walking a lot can give benefits to my health & $1(0.6)$ & $3(1.9)$ & 0 & $40(25.2)$ & $115(72.3) *$ \\
\hline I should take fruit or vegetable in my diet for maintaining my health & $1(0.6)$ & 0 & $5(3.1)$ & $30(18.9)$ & $123(77.4)^{*}$ \\
\hline I should control my stress to avoid from getting any disease & $1(0.6)$ & $2(1.3)$ & $4(2.5)$ & $44(27.7)$ & $108(67.9) *$ \\
\hline
\end{tabular}

*Expected answer

The highest response is in bold 
Table 4: Practice regarding Risk Factors of CVD $(\mathrm{n}=159)$.

\begin{tabular}{|c|c|c|c|c|}
\hline \multirow{2}{*}{ Questions } & \multicolumn{4}{|c|}{ Frequency, n (\%) } \\
\hline & Never & Seldom & Frequently & Always \\
\hline Does your daily activity involve vigorous activity? (E.g. heavy lifting, digging) & $34(21.4)$ & $97(61.0) *$ & $18(11.3)$ & $10(6.3)$ \\
\hline Do you walk for at least 10 minutes to get to and from places such as café, classes, mosque etc.? & $4(2.5)$ & $36(22.6)$ & $37(23.3)$ & $82(51.6) *$ \\
\hline Do you spend your leisure time to exercise at least 20 minutes per session? & $16(10.1)$ & $92(57.9)$ & $29(18.2)$ & $11(13.8)^{*}$ \\
\hline Do you take any supplement or special diet? E.g. Evening Primrose oil, oat diet & $71(44.7)$ & $34(21.4)$ & $20(12.6)$ & $34(21.4)^{*}$ \\
\hline How often do you take fruits in your diet? & $2(1.3)$ & $102(64.2)$ & $33(20.8)$ & $22(13.8)^{*}$ \\
\hline How often do you take vegetables in your diet? & $5(3.1)$ & $29(18.2)$ & $50(31.4)$ & $75(47.2) *$ \\
\hline How often do you eat fast food? & $5(3.1)^{*}$ & $124(78.0)$ & $21(13.2)$ & $9(5.7)$ \\
\hline Do you take fried food as your main course? & $6(3.8)$ & $45(28.3)^{*}$ & $79(49.7)$ & $29(18.2)$ \\
\hline Do you like to eat in between main meals? (E.g. snacking, eating biscuits, etc.) & $7(4.4)$ & $67(42.1) *$ & $52(32.7)$ & $33(20.8)$ \\
\hline Do you lead a stressful life? & $19(11.9) *$ & $90(56.6)$ & $42(26.4)$ & $8(5.0)$ \\
\hline
\end{tabular}

*Expected answer

The highest response is in bold

Table 5: Comparison of Total Knowledge Scores between Gender, Faculty and Year of Study using Anova Test (N=159).

\begin{tabular}{|c|c|c|c|c|}
\hline & $\mathbf{n}$ & Mean (SD) & $F$-statistics $(d f)$ & $p$-value \\
\hline \multicolumn{5}{|l|}{ Gender } \\
\hline Male & 36 & $43.06(2.43)$ & 0.042 & \multirow[t]{2}{*}{0.837} \\
\hline Female & 123 & $42.96(2.48)$ & $(1,157)$ & \\
\hline \multicolumn{5}{|l|}{ Faculty } \\
\hline Science & 26 & $41.12(3.18)$ & 7.944 & \multirow[t]{6}{*}{$<0.001$} \\
\hline Pharmacy & 32 & $44.34(1.68)$ & $(5,153)$ & \\
\hline Medicine & 21 & $44.29(1.49)$ & & \\
\hline Allied Health Sciences & 24 & $42.92(2.43)$ & & \\
\hline Dentistry & 34 & $42.82(2.04)$ & & \\
\hline Nursing & 22 & $42.27(2.23)$ & & \\
\hline \multicolumn{5}{|l|}{ Year of Study } \\
\hline 1 & 33 & $42.55(2.31)$ & 0.668 & \multirow[t]{4}{*}{0.573} \\
\hline 2 & 48 & $43.10(2.46)$ & $(3,155)$ & \\
\hline 3 & 43 & $43.30(2.37)$ & & \\
\hline 4 & 35 & $42.83(2.75)$ & & \\
\hline
\end{tabular}

= standard deviation

$d f=$ degree of freedom

Table 6: Comparison of Total Attitude Scores between Gender, Faculty and Year of Study using Anova Test (N=159).

\begin{tabular}{|c|c|c|c|c|}
\hline & $\mathbf{n}$ & Mean (SD) & $F$-statistics $(d f)$ & $p$-value \\
\hline \multicolumn{5}{|l|}{ Gender } \\
\hline Male & 36 & $54.78(7.43)$ & 8.124 & 0.005 \\
\hline Female & 123 & $57.80(4.96)$ & $(1,157)$ & \\
\hline \multicolumn{5}{|l|}{ Faculty } \\
\hline Science & 26 & $57.27(4.94)$ & 1.447 & 0.211 \\
\hline Pharmacy & 32 & $55.59(5.23)$ & $(5,153)$ & \\
\hline Medicine & 21 & $59.10(3.94)$ & & \\
\hline Allied Health Sciences & 24 & $56.79(4.15)$ & & \\
\hline Dentistry & 34 & $58.24(5.22)$ & & \\
\hline Nursing & 22 & $55.91(9.49)$ & & \\
\hline \multicolumn{5}{|l|}{ Year of Study } \\
\hline 1 & 33 & $56.88(7.63)$ & 0.268 & 0.848 \\
\hline 2 & 48 & $56.67(4.93)$ & $(3,155)$ & \\
\hline 3 & 43 & $57.30(4.55)$ & & \\
\hline 4 & 35 & $57.74(6.15)$ & & \\
\hline
\end{tabular}

$\mathrm{SD}=$ standard deviation

$d f=$ degree of freedom

\section{Comparing KAP regarding CVD Risk Factors between different Socio-demographic Characteristics}

In comparing the total knowledge scores, there is no significant difference between males and females $(p=0.837)$ or between the different years of study ( $p=0.573$ ).

On the other hand, significant difference was found between the different faculties $(p<0.001)$. The post-hoc test shows that the significance difference lies between the Faculty of Science with Faculty of Medicine $(p<0.001)$, Pharmacy $(p<$ $0.001)$ and Dentistry $(p=0.043)$. The other significant differences were between the Faculty of Nursing with Faculty of Pharmacy $(p=0.013)$ and Medicine $(p=0.041)$. The full results are shown in Table 5. The comparison of total attitude scores shows a significant difference between males and females $(p=0.005)$, similarly for the comparison of total practice scores $(p=0.017)$ with females showing better attitude and practice. However, there was no significant difference in comparing the total attitude and practice scores between the different faculties $(p=0.211$ and 0.356 , respectively) or between the different years of study ( $p=$ 0.848 and 0.652 , respectively). The full results for comparing the total attitude and practice scores are shown in Table 6 and 7, respectively. 
Table 7: Comparison of Total Practice Scores between Gender, Faculty and Year of Study using Anova Test (N=159).

\begin{tabular}{|c|c|c|c|c|}
\hline & $\mathbf{n}$ & Mean (SD) & $F$-statistics $(d f)$ & $p$-value* \\
\hline \multicolumn{5}{|l|}{ Gender } \\
\hline Male & 36 & $25.44(3.89)$ & 5.825 & 0.017 \\
\hline Female & 123 & $27.02(3.32)$ & $(1,157)$ & \\
\hline \multicolumn{5}{|l|}{ Faculty } \\
\hline Science & 26 & $27.50(3.05)$ & 1.112 & 0.356 \\
\hline Pharmacy & 32 & $26.38(3.54)$ & $(5,153)$ & \\
\hline Medicine & 21 & $27.43(4.71)$ & & \\
\hline Allied Health Sciences & 24 & $26.75(4.09)$ & & \\
\hline Dentistry & 34 & $26.59(2.87)$ & & \\
\hline Nursing & 22 & $25.41(2.72)$ & & \\
\hline \multicolumn{5}{|l|}{ Year of Study } \\
\hline 1 & 33 & $26.67(3.94)$ & 0.545 & 0.652 \\
\hline 2 & 48 & $26.23(3.77)$ & $(3,155)$ & \\
\hline 3 & 43 & $26.70(2.96)$ & & \\
\hline 4 & 35 & $27.23(3.51)$ & & \\
\hline
\end{tabular}

SD = standard deviation

$d f=$ degree of freedom.

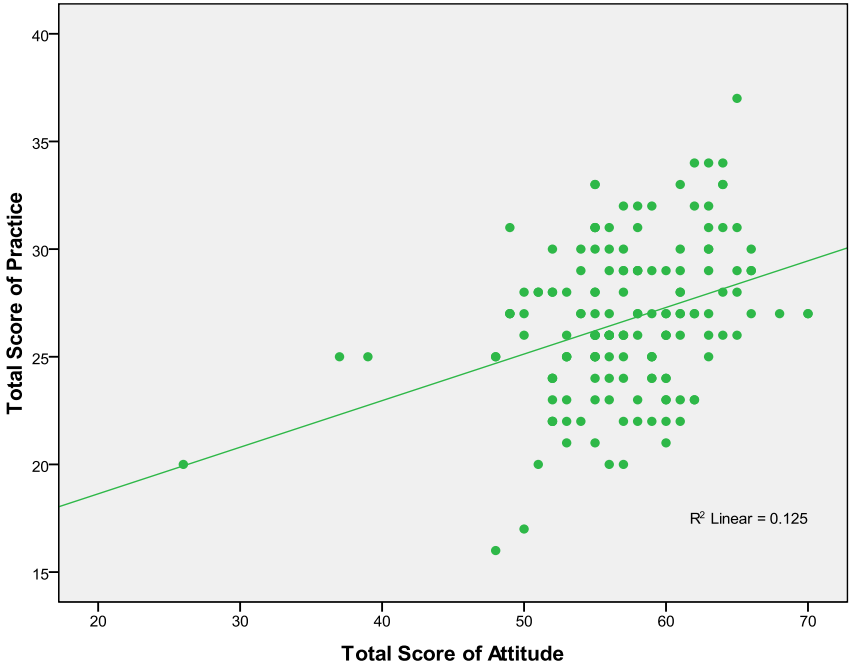

Fig. 1: Correlation between Total Scores of Attitude and Practice

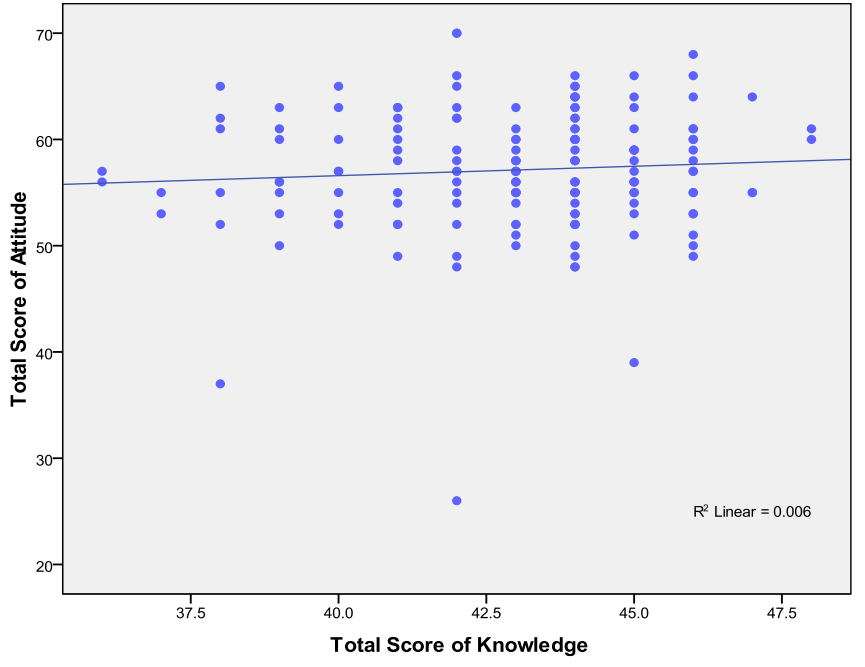

Fig. 2: Correlation between Total Scores of Knowledge and Attitude

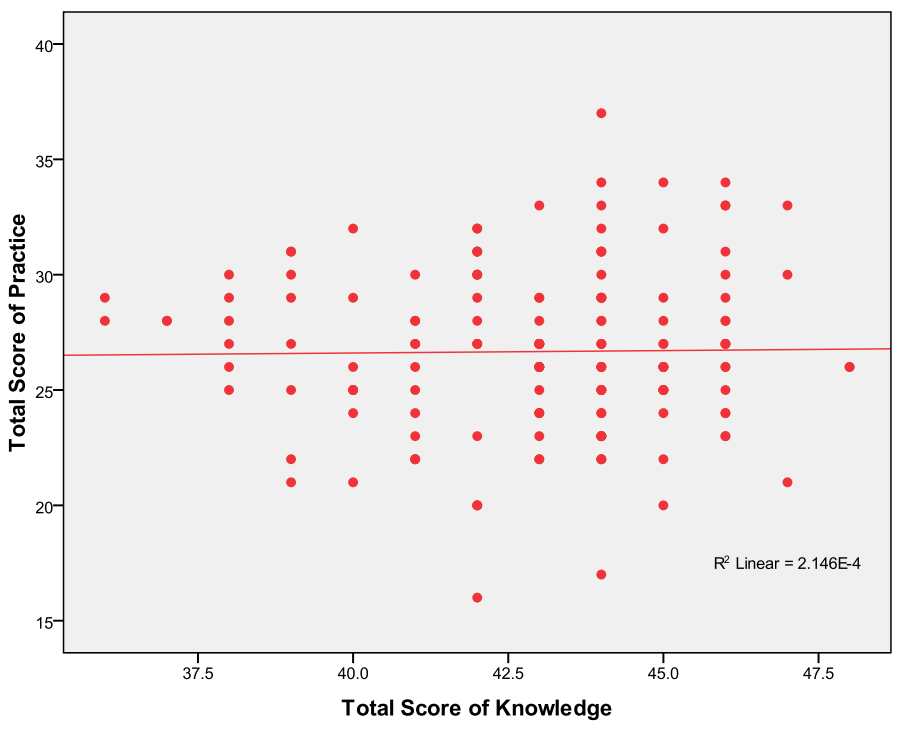

Fig. 3: Correlation between Total Scores of Knowledge and Practice. 


\section{The Correlation between KAP regarding CVD Risk Factors}

There was a significant positive correlation between total attitude and practice scores with $r=+0.354(p<0.001)$ as shown in Figure 1. However, there was no significant correlation between total knowledge and attitude scores $(r=+0.076, p=0.341)$ or between total knowledge and practice scores $(r=+0.015$, $p=0.855)$ as shown in Figure 2 and 3, respectively.

\section{DISCUSSION}

Statistics have shown that CVD is the leading cause of death in Malaysia. The disease can be prevented by increasing the level of awareness regarding the causes or risk factors of CVD. The low level of knowledge might lead to bad attitudes and poor practice of healthy lifestyles. In this study, the proportion of having family members who have CVD was quite prominent, with father topped the list, followed by mother, siblings and others. Others here include grandparents, aunts and uncles with a history of CVD such as heart attack, stroke or hypertension. The gender distribution of patient with Acute Coronary Syndrome shows that male percentages were three times higher than female (Chin et al., 2008).

The prevalence of hypertension in Malaysia was very high as it was one of the main risk factors of mortality (Rampal et al., 2008; Kiau et al., 2013) and the result from this study supported this fact, with almost half of the respondents' family has suffered from hypertension. These findings were comparable to the studies of women in North-East coast Malaysia where hypertension was the main reported risk factors in the family of the respondents (Rosediani et al., 2012). As IIUM Kuantan Campus consisted of health-related programs, most of the respondents had learnt and known about CVD from their classrooms, while only one program did not directly received the formal learning on CVD which was the Computational and Theoretical Science program from the faculty of science. However, the knowledge could easily be obtained from books in the library and from the internet. Diabetes has become one of the most critical risk factors that cause CVD, but the result shows that quite a number of respondents did not know about this fact. This was quite similar to the study carried out on young African American adults (Winham et al., 2011). This may be due to the lack of information. Furthermore, the sedentary lifestyle is also one of the risk factors of CVD. $68 \%$ answered correctly when asked about the conditions related to CVD. The results were in line with the findings of another study (Winham et al., 2011). There was a poor response for 'False' answer to the question regarding heredity as one of the risk factors for CVD. Similar findings have also been reported from the United States of America (USA) (Lynch, 2006).

There was a high possibility of premature CVD to be inherited, but most of CVD incidence was due to behavioral changes and lifestyles (Khadeeja, 2008). University students are very likely to have a sedentary kind of lifestyle since they spent a lot of times doing assignment and study. $12 \%$ of subjects did not walk, but took other means of transportation, even for very near places.

This can be explained as most Malaysians own at least a car or motorcycle. The score for vigorous activity was low (61\%) and this finding conveys the lack of physical activity in their daily life of the respondents. In addition, $10-58 \%$ of the respondents rarely or never do physical exercise. This suggests that our respondents were not keen to engage in exercise. These situations will likely result in lesser calorie expenditure, causing obesity and later, CVD (Wong et al., 2000). The fruit intake was quite low $(62 \%)$, however, the vegetable intake has been more often $(81 \%)$, so that the healthy diet intake still preserved. Unfortunately, more than half of the subjects were taking fried food as the main course. The excessive oil and fat intake may increase the other risk factors of CVD (Canoy, 2008). 54\% of the respondents have the habit of snacking between meals. This habit has its own pros and cons, while it might reduce the hunger and avoid from eating too much during the main meal, but may increase craving for snacks and sweets which can cause the obesity and other disorders. The content of the snacks should be consistent with the suggested eating pattern to limit the fat and cholesterol intake (Davidson et al., 2000). The trend of eating fast food has increased as the urbanization expanded and in the long run it would affect the diet pattern of people, leading to high cholesterol level and obesity (Nishtar, 2002; Asia Pacific Cohort Studies Collaboration, 2003; Aarabi and Jackson, 2007; Ueshima et al., 2008; Ajay and Prabhakaran, 2010; Hurt et al., 2010; Malik et al., 2012).

This study also found that almost half of the respondents thought that they cannot manage their stress. Stress management plays such an important role in managing the risk factor of CVD as likely to cause heart disease (The American Institute of Stress; Khayyam-Nekouei et al., 2013). A study found that $86 \%$ subjects believed that reducing stress was one of the ways to prevent or reduce the heart disease occurrence (Winham et al., 2011). Our respondents also have similar views regarding stress. The response to tobacco cessation program also was quite low. This might be because not much attention was given by the mass media to promote the program to the public.

On the other hand, there was a significant difference between the mean total scores of knowledge between the different faculties. This indicated the distinct level of knowledge acquired by each faculty. Other studies reported that there were differences regarding knowledge of heart disease between gender and education level (Winham et al., 2011). However, this study has found that there was no difference between genders in term of knowledge. It proves that women have a better attitude than men. This finding is correlated with another study (Rosediani et al., 2012). Furthermore, the practice result has also illustrated that the difference between genders as significant, opposite to a study done on young adults in the USA (Lynch et al., 2006). This might be caused by the imbalanced number of male and female proportion in this study. 
The correlation test shows a significant, but moderate and positive relationship between the total attitude and practice scores of the respondents. This indicated that the level of practices would likely increase when their attitude was better. This finding is supported by another study regarding the process of behavior change (Prochaska and DiClemente, 1983). Knowledge did not have a significant association to both attitude and practice, and it is proven that having high knowledge alone did not guarantee the behavioral modification (Potvin et al., 2000). As the tendency of the respondents to be associated with a sedentary lifestyle, lack of exercise, poor diet with stressful life, these factors turn out to be challenging for them to implement and maintain a healthy standard of living (Kulkayeva et al., 2012). There should be more campaigns regarding healthy lifestyles on campus to promote the young generation towards zero diseases and free from the CVD risk factors.

\section{CONCLUSION}

This study suggests that IIUM Kuantan students should increase their level of practice in preventing the occurrence of CVD. The levels of knowledge were quite high, but it conveys no relation to the level of attitude or practices. There is a significance difference between the different faculty in terms of knowledge while for attitude and practice, there are significant differences between males and females. Even though there is the positive correlation between attitude and practice, it is just a moderate relationship showing the practice could be increased when attitude is better. This is a cross-sectional study with its own limitation. Future studies are recommended for a better assessment.

\section{ACKNOWLEDGEMENT}

Authors are much grateful to those students who participated in this study. Authors are also much thankful to IIUM Kuantan authority for all cooperation extended to this study.

\section{REFERENCES}

Aarabi M, Jackson PR. Prevention of coronary heart disease with statins in UK South Asians and Caucasians. Eur J Cardiovasc Prev Rehabil, 2007; 14(2):333-339.

Ajay VS, Prabhakaran D. Coronary heart disease in Indians: Implications of the INTERHEART study. Indian J Med Res, 2010; 132(5): 561-566.

Asia Pacific Cohort Studies Collaboration. Cholesterol, coronary heart disease, and stroke in the Asia Pacific region. Int $\mathbf{J}$ Epidemiol, 2003; 32 (4):563-572.

Canoy D. Distribution of body fat and risk of coronary heart disease in men and women. Curr Opin Cardiol, 2008; 23 (6): 591-600.

Cardiovascular Consultants. Cardiac Risk Factors. 2006. http://www.cardioconsult.com/RiskFactors/

Chin SP, Jeyaindran S, Azhari R, Azman WAW, Omar I, Robaayah Z, Sim KH. Acute Coronary Syndrome (ACS) Registry Leading the Charge for National Cardiovascular Disease (NCVD) Database. Med J Malaysia, 2008; 63 (Supplement C): 29-36.

Davidson DM, Traum CI, Stone EJ, Nathan WD. Children and Adolescents. In: Wong ND, Black HR, Gardin JM. Preventive Cardiology. USA: McGraw-Hill. New York, USA. 2000
Gaziano TA, Bitton A, Anand S, Abrahams-Gessel S, Murphy A. Growing Epidemic of Coronary Heart Disease in Low- and MiddleIncome Countries. Curr Probl Cardiol, 2010; 35(2):72-115.

Grundy SM, Pasternak R, Jr Smith S, Fuster V. Assessment of Cardiovascular Risk by Use of Multiple-Risk-Factor Assessment Equations. A Statement for Healthcare Professionals from the American Heart Association and the American College of Cardiology. Circulation, 1999; 100: 1481-1492.

Hurt RT, Kulisek C, Buchanan LA, McClave SA. The Obesity Epidemic: Challenges, Health Initiatives, and Implications for Gastroenterologists. Gastroenterol Hepatol (N Y). 2010; 6(12): 780-792.

Institute of Medicine (US) Committee on Preventing the Global Epidemic of Cardiovascular Disease: Meeting the Challenges in Developing Countries; Fuster V, Kelly BB, editors. Promoting Cardiovascular Health in the Developing World: A Critical Challenge to Achieve Global Health. Washington (DC): National Academies Press (US); 2010. 2, Epidemiology of Cardiovascular Disease. Available from: http://www.ncbi.nlm.nih.gov/books/NBK45688/

Khadeeja A. Accessibility to Knowledge and Information on Risk Factors and Prevention of Cardiovascular Diseases and Preventive Behaviors of Residents above 30 years in Male'-Maldives. Thesis, Master of Public Health. Chulalongkorn University. 2008 http://cuir.car.chula.ac.th/handle/123456789/20250?src=/sidebar/thesis.jsp $\% 5 \mathrm{Bques} ; \% 5 \mathrm{Dtemp}=1 \% 5 \mathrm{Bamp} ; \% 5 \mathrm{Dbrw} \_$pos=29\%5Bamp;\%5Dbrw_tota $1=36038$

Khayyam-Nekouei Z, Neshatdoost H, Yousefy A, Sadeghi M, Gholamreza Manshaee G. Psychological factors and coronary heart disease. ARYA Atheroscler, 2013; 9(1): 102-111.

Kiau HB, Kaur J, Nainu BM, Omar MA, Saleh M, Keong YW, Hock LK. Prevalence, awareness, treatment and control of Hypertension among the elderly: the 2006 National Health and Morbidity Survey III in Malaysia. Med J Malaysia, 2013; 68 (4): 332-337.

Kulkayeva G, Harun-Or-Rashid M, Yoshida Y, Tulebayev K, Sakamoto J. Cardiovascular Disease Risk Factors among Rural Kazakh Population. Nagoya J Med Sci, 2012; 74 (1-2): 51-61.

Linda M. Knowledge, Attitude and Practices Towards Risk Factors for Hypertension in Kinondoni Municipality, Dar Es Salaam. DMSJ, 2007; 14 (2): 59-62.

Lynch EB, Liu K, Kiefe CI, Greenland P. Cardiovascular Disease Risk Factor Knowledge in Young Adults and 10-year Change in Risk Factors. Am J Epidemiol, 2006; 164 (12): 1171-1179.

Malik VS, Willett WC, Hu FB. Global obesity: trends, risk factors and policy implications. Nature Reviews Endocrinology. 2012 http://isites.harvard.edu/fs/docs/icb.topic1124294.files/Global\%20obesity $\% 20$ NatureReviews.pdf

Nishtar S. Prevention of coronary heart disease in south Asia. Lancet, 2002; 360(9338):1015-1018.

Potvin L, Richard L, Edwards AC. Knowledge of cardiovascular disease risk factors among the Canadian population: relationship with indicators of socioeconomic status. CMAJ, 2000; 162 (9 Suppl): S5-11.

Prochaska JO, DiClemente CC. Stages and processes of selfchange of smoking: Toward an integrative model of change. Journal of Consulting and Clinical Psychology, 1983; 51, 390-395.

Rampal L, Rampal S, Azhar MZ, Rahman AR. Prevalence, awareness, treatment and control of hypertension in Malaysia: A national study of 16,440 subjects. Public Health, 2008; 122 (1): 11-18.

Rampal L, Somayeh AB, Salmiah MS, Faisal I, Zainiyah SYS. Prevalence of Hypertension and its Associated Factors among University Staff. Malay J Med Health Sci, 2011; 7 (2): 61-71.

Rosediani M, Ranimah Y, Harmy MY. Knowledge, Attitude and Practice on Cardiovascular Disease among Women in North-East Coast Malaysia. International Journal of Collaborative Research on Internal Medicine \& Public Health, 2012; 4 (1): 85-98.

Smith, S. et al. Urbanization and cardiovascular disease: Raising heart-healthy children in today's cities. [pdf] Geneva: The World Heart Federation. 2012. Available at: http://www.worldheart.org/ urbanization 
Texas Heart Institute. Heart Disease Risk Factors for Adults. 2015. http://www.texasheart.org/HIC/Topics/HSmart/riskfact.cfm

The American Institute of Stress. Stress and Heart Disease. 6387B Camp Bowie Blvd \# 334 Fort Worth, TX 76116 USA. http://www.stress.org/stress-and-heart-disease/

Ueshima H, Sekikawa A, Miura K, Turin TC, Takashima N, Kita Y, Watanabe M, Kadota A, Okuda N, Kadowaki T, Yasuyuki Nakamura Y, Okamura T. Cardiovascular Disease and Risk Factors in Asia A Selected Review. Circulation, 2008; 118: 2792-2709.

Wilson PWF, D'Agostino RB, Levy D, Belanger AM, Silbershatz H, Kannel WB. Prediction of Coronary Heart Disease Using Risk Factor Categories. Circulation, 1998; 97: 1837-1847.

Winham DM, Jones KM. Knowledge of young African American adults about heart disease: a cross-sectional survey. BMC Public Health, 2011; 11: 248.

Wong ND, Black HR, Gardin JM. 2000. Preventive Cardiology. USA: McGraw-Hill. New York, USA.
World Health Organization. Factsheet No. 317 - Cardiovascular Diseases. [Online] Geneva: World Health Organization. 2011a. Available at: http://www.who.int/mediacentre/factsheets/fs317/en/index.html

World Health Organization. Global status report on noncommunicable diseases 2010. 2011b. WHO Press, World Health Organization, 20 Avenue Appia, 1211 Geneva 27, Switzerland. Available at: http://www.who.int/nmh/publications/ncd_report_full_en.pdf

\section{How to cite this article:}

Ibrahim MM, Rahman NAA, Rahman NIA, Haque M. Knowledge, Attitude and Practice of Malaysian Public University Students on Risk Factors for Cardiovascular Diseases. J App Pharm Sci, 2016; 6 (02): 056-063. 